\title{
Research on Chinese College English Teachers' Classroom Code-switching: Beliefs and Attitudes
}

\author{
Xiaoli Cheng \\ Chongqing Normal University, Chongqing, China
}

\begin{abstract}
This article documents the beliefs and attitudes of Chinese college English teachers towards classroom code-switching. The findings suggest that teachers' code-switching is commonplace in class, although most of them still hold negative attitude toward it. Besides, students' ability is regarded as the most significant factor affecting teachers' code-switching, and the first language (L1) is mainly used to teach grammar and abstract words. The conclusion is that, in Chinese English as a foreign language (EFL) context, classroom code-switching should be conducted on the basis of maximal use of the target language, and the L1 can only be judiciously employed to serve difficult and abstruse subject matters.
\end{abstract}

Index Terms - classroom code-switching, Chinese, English, maximal use

\section{INTRODUCTION}

During the past decades, the tentative use of the first language (L1) in second or foreign language classroom is widely documented in the literature (Atkinson, 1987; Duff \& Polio, 1990, 1994; Harbord, 1992; Swain \& Lapkin, 2000), and the question receiving the most heated debate usually focuses on whether the L1 is a resource or an impediment to the acquisition of the target language. The answer to this question is a mixed one, just as Cook (2001, p.403) commented that language teaching methodology should be responsive to diverse goals, therefore, "the question of using the L1 may not have a single answer suitable to all teaching goals". This being so, researchers such as Turnbull (2001) and Turnbull \& Arnett (2002) proposed to first examine such questions as when, why and how much the L1 and the target language should be employed in the pedagogy, so as to make judicious and principled use of the L1, while maximizing the target language use.

However, most of the aforementioned research investigated second or foreign language teaching in English speaking countries. Limited research about the choice of instructional medium was conducted in English as a foreign language context (Macaro, 2001). Besides, what does maximal target language use mean in differing educational settings? The present research, which is a pilot one, intends to analyze the beliefs and attitudes of Chinese college English teachers towards classroom code-switching. These beliefs and attitudes are likely to exert a strong influence on their lesson planning (Woods, 2003), and how teachers respond to the use of the L1 or target language will crucially affect the performance of their students (Rubdy, 2007).

The literature abounds in studies on teachers' beliefs and attitudes towards classroom code-switching (Macaro, 1997; Liu et al., 2004; Rubdy, 2007), and two extremes of opinions are identified. The lay public and some English teachers hold the opinion that foreign language teaching should be conducted only in English. To them, English-only in foreign language classroom is too self-evident to be worth any specific expositions. This group of teachers manages to exclude the L1 from their classes for fear that the use of the L1 will impede progresses in the acquisition of English. They usually feel greatly discouraged or even guilty whenever they stray away from the English-only path. In contrast, another portion of teachers usually overuses the L1 in foreign language teaching. To them, the traditional grammar-translation method is still effective enough to impart foreign language knowledge to learners with differing language proficiency. In China, with the introduction of communicative language teaching and task-based teaching method, together with the emphasis on improving the comprehensive ability of students and the theoretical qualifications of foreign language teachers, what beliefs are embraced by college English teachers towards classroom code-switching? Without definite guidance from authorities, what stances are adopted by them?

\section{LITERATURE REVIEW}

In the classroom of foreign language teaching, code-switching refers to teachers' choice of languages between the foreign language being taught and the language of the school or society (Simon, 2000, p.312). In such situation, the teachers are usually non-native speakers of the target language, sharing the same mother tongue with their students. Macaro (2005) called these non-native teachers bilingual teachers. In China, most of the English teachers are bilingual, with Mandarin their L1, and English the foreign language.

From the perspective of social interaction, with the globalization of work locations, people are required to possess verbal mastery and discursive power in differing languages or language varieties (Mesthrie, 2000). Thus, the ability to switch code from one language to another will be valued as a communicative resource (Gumperz, 1982), a type of 
literacy which will be crucially desired in the future societies. However, in the context of classroom formal education, code-switching tends to be treated as a "forbidden" practice. The history of this classroom monolingual attitude can be traced back to the Americanization movement in the early $20^{\text {th }}$ century when nativism and anti-foreign political sentiment resurged in the United States. It is also related with the colonial and neocolonial eras, when British employed English to realize its dominant role in the world. Now the English-only teaching method is criticized as a form of linguistic imperialism aiming to protect existing power relations (Phillipson, 1992). It can also cause the loss or downgrading of some native languages and the related cultures (Van der Walt, 1997).

\section{A. Theoretical Perspectives of Target Language-only Method}

The input hypothesis provides the strongest rationale for target language-only practice in foreign language class. According to Krashen and Terrell (1983), language input plays a significant role in the course of language learning. Therefore, foreign language classrooms should be a source of input, a place where learners can be exposed to sufficient comprehensible input. Turnbull (2001) also emphasizes the importance of maximum language input in class, especially when the classrooms are the only places where the target language can be encountered. However, the importance of language input is exaggerated, which is manifested in the tenets issued in a conference held in 1961. For example, "the more English is taught, the better the results; if other languages are used too much, standards of English will drop" (Auerbach, 1993, p.12). After the dissemination of these tenets, the exclusion of the L1 from foreign language classes is thought to be natural and reasonable.

Language compartmentalization theory lends its support to target language-only practice (Cook, 2001). According to this theory, the target language and the L1 are "coordinate bilingualism" instead of a single "compound bilingualism". Therefore, the target language learning can be developed without any involvement of the L1. This theory has now been overthrown with the development of psycholinguistics and cognitive linguistics. The two languages in human mind are proved to be interwoven in different levels (ibid.).

Motivation is the affective factor underpinning classroom language monolingualism. MacDonald (1993) contends that teachers' consistent use of the target language can arouse students' awareness of its immediate usefulness. Therefore, students are more likely to set instrumental goals to learn and use the target language in and out of class. Likewise, insufficient use of the target language by teachers will de-motivate learners to be dependent on the native language.

However, none of these theories are conclusively and pedagogically sound in justifying the rationality of classroom monlingualism. In actuality, no matter how hard we close the door for the L1, it still creeps into foreign language classrooms. Rather than facing it with guilt in class, teachers can, in effect, make sensible and systematic use of it (Cook, 2001). Macaro (2005) also indicates explicitly that code-switching should become one of the objectives in curriculum planning. As to the worries about insufficient language input and de-motivation, research indicates that mere comprehensible input is far from enough for language input to become intake. Pushed language output (Swain, 1993) and negotiation of meaning (Long, 1996) are also critical in the process of language learning. Besides, Code-switching is a natural phenomenon in settings where learners share two languages (Turnbull \& Arnett, 2002). Access to the L1 enables the students to accomplish tasks more successfully (Swain \& Lapkin, 2000), especially to those students who are not cognitively matured. So, judicious use of the L1 won't de-motivate but motivate students to acquire language. Denying access to the $\mathrm{L} 1 \mathrm{will}$ deprive students of a precious cognitive tool (ibid.).

In the literature, the tentative functions of the L1 in foreign language or L2 classes are myriad. It can facilitate teacher-student communication, establish teacher-student rapport and most important of all, assist language learning (Harbord, 1992). Code-switching is frequently noticed when teachers are checking comprehension, highlighting important point and attracting attention, etc. (Liu et al., 2004). The motives behind teachers' classroom language choices concern the teaching methods adopted, pressure from rules or policies, teachers' ability, etc. So, the focus in the present research is not to contend whether the L1 can be employed or not, but to specify Chinese college English teachers' beliefs and attitudes towards the possible functions, reasons and ratios of code-switching in the context of foreign language teaching. The question of maximal target language use will also be explored by means of teachers' reflections and self-evaluations.

\section{B. Official Stances towards Classroom Code-switching}

In terms of the official attitudes to classroom code-switching, the existing education planning policies demonstrate three positions in general (Ferguson, 2003, p.46): strict separation of languages; concurrent but systematized and controlled use of the two languages; acceptance of code-switching and awareness-raising through teacher education. Countries or regions such as Singapore, Hong Kong, England and Wales strictly ban the presence of the L1s in the foreign language classrooms. In Singapore, Singlish is even regarded as "a threat to the nation's competitive advantage in the global marketplace" (Rubdy, 2007, p.308, wrongly in her opinion). Hong Kong government stipulates that teaching or learning should only be conducted in English or Chinese medium. Mixed-code should be reduced as far as possible (Education Commission Report No. 4 1990, cited in Lin, 2000, p.183). As to the concurrent, yet controlled use of the L1 and the target language, the best known example is the 'New Concurrent Approach' in the United States for bilingual Spanish-English classrooms. However, this standpoint is criticized as mechanic and infeasible (Ferguson, 2003) due to the fact that code-switching usually occurs in dynamic and ongoing classroom discourse. Therefore, it's difficult to control it or put it into a prefabricated format. The third attitude is regarded as the most persuasive one due to its 
acceptance of reality and incorporation with teacher education. However, the greatest problem comes from its implementation, that is, to convince educational authorities of the legitimacy and utility of classroom code-switching so as to make adjustments to teacher education curricula (ibid.).

In Chinese tertiary foreign language teaching context, the official stance towards classroom code-switching is undetermined or hazy. According to Ferguson (2003), foreign language classes can be classified into language subject and content subject class. The former aims to improve students' mastery of the target language knowledge, say, grammar, pronunciation, vocabulary, or to cultivate students' target language communicative abilities. The principal aim of the latter is to ensure students' understanding and mastery of the subject matter. Therefore, any methods contribute to that subject deserve sympathetic consideration. In Chinese EFL context, most of the foreign language classes are language subject oriented, which makes the argument for using the L1 seem less secured. National curricula of various versions clearly prescribe the requirements and measures taken to realize the goal. However, regarding the choice of classroom instructional medium, more exactly, the relations between Chinese and English, explicit and detailed suggestions can hardly be found. Teaching Curriculum for English Majors at Elementary Level (1996) requires that foreign language classes should be organized in English from the outset for the purpose of strengthening the sense of English, or creating an optimal foreign language learning atmosphere. Although it points out that the use of English doesn't reject the possible functions of the L1, no further explanations were made on it. In Teaching Curriculum for English Majors (2000), only one line was devoted to the question of instructional code, that is, generally speaking, English should be the instructional medium. The newly-issued College English Curriculum Requirements (2007) provides no suggestions on the use of English or Chinese either. However, this new version highly values the importance of listening and speaking for the sake of improving the communicative abilities of college students. It also proposes to make assessment not only on students but teachers, say, teaching attitudes, teaching methods, teaching organization, etc. In such case, classroom code-switching as a kind of pragmatic or communicative strategy for teachers and students shouldn't continue to be neglected in the future.

\section{RESEARCH DESIGN}

\section{A. Research Questions}

This study deals with Chinese college English teachers' beliefs and attitudes concerning classroom code-switching in terms of three aspects: first, what is the proportions of Chinese and English in foreign language teaching? Second, what are the functions and reasons of classroom code-switching? Finally, what does maximal target language use mean in Chinese tertiary EFL settings?

\section{B. Participants}

The investigation is conducted among the members of a teacher training program in Singapore. The participants involved are 32 Chinese English teachers $(n=32)$ at tertiary level. They come from 28 universities and colleges throughout China, including comprehensive key universities, key international studies universities, normal universities, science and technology universities and ordinary teacher education colleges, etc. In the sample, twenty-six teachers are female, and six male. Thirteen of them teach English majors, fifteen of them teach non-majors, and the rest teach both English majors and non-majors. Their years of teaching vary from three to fourteen years. Therefore, generally speaking, the participants involved are qualified to represent the mainstream Chinese foreign language teachers at tertiary level. For ethical reasons, more detailed information about them is not provided. In addition, the participants are not provided with any forms of lectures on classroom codes-switching. However, it doesn't exclude the possibility that they may read materials about this topic by themselves.

\section{Methods}

A semi-structured questionnaire, which is designed on the basis of Liu et al.'s (2004) research, is conducted. It contains four multiple choice questions and three open-ended questions. Two of the multiple choice questions are about teachers' actual and ideal target language use in class respectively. Another two are about the reasons and functions of classroom code alternation. The three open-ended questions mainly concern teachers' reflections and comments on their use of Chinese or English in class.

Research on teachers' beliefs and attitudes tends to borrow interview (Sakui \& Gaies, 2003). Therefore, in order to guarantee that more in-depth background information can be uncovered, the present research interviews seven teachers, who claim to use different proportions of the L1 and target language. The interview is conducted in a person to person mode, and the time span for each participant extends from 5 to 15 minutes. Besides, two more questions are added in the interview. One is about teachers' understanding of classroom and social code-switching; the other concerns the goals of foreign language teaching. Both of them are closely related with the nature and functions of code-switching in foreign language classrooms.

\section{DATAANALYSIS}

\section{A. Proportions of the Target Language Use}


In order to determine whether the teachers differ significantly in terms of target language use, SPSS 16.0 is adopted. First, one-way Chi-Square test is applied to the actual and ideal target language use respectively (TABLE 2). Then two-way Chi-Square test is used to compare the differences between the actual and ideal target language use (TABLE 3). TABLE 1 presents the original data from the questionnaire.

TABLE 1.

THE NUMBER OF TEACHERS TO EACH PROPORTION OF TARGET LANGUAGE USE

\begin{tabular}{|c|c|c|c|c|c|c|c|}
\hline & $0 \%-50 \%$ & $51 \%-60 \%$ & $61 \%-70 \%$ & $71 \%-80 \%$ & $81 \%-90 \%$ & $91 \%-99 \%$ & $100 \%$ \\
\hline Actual & 1 & 1 & 5 & 6 & 8 & 10 & 1 \\
\hline Ideal & $\mathbf{0}$ & 0 & 0 & 2 & 8 & 18 & 4 \\
\hline
\end{tabular}

TABLE 2

ONE-WAY CHI-SQUARE FOR THE ACTUAL AND IDEAL TARGET LANGUAGE USE

\begin{tabular}{|l|l|l|}
\hline \multicolumn{1}{|l}{ ONE-WAY CHI-SQUARE FOR THE ACTUAL AND IDEAL TARGET LANGUAGE USE } \\
\hline Chi-Square & Actual proportion & Ideal proportion \\
\hline df & 17.875 & 19.000 \\
\hline Asymp. Sig. & 6 & 3 \\
\hline
\end{tabular}

TABLE 3

TWO-WAY CHI-SQUARE FOR THE DIFFERENCE BETWEEN ACTUAL AND IDEAL TARGET LANGUAGE USE

\begin{tabular}{|l|l|l|l|}
\hline \multicolumn{2}{|l|}{ TWO-WAY CHI-SQUARE FOR THE DIFFERENCE BETWEEN ACTUAL AND IDEAL TARGET LANGUAGE USE } \\
\hline Pearson Chi-Square & Value & $\mathrm{df}$ & Asymp. Sig.(2-sided) \\
\hline Likelihood Ratio & 32.919 & 18 & .017 \\
\hline Linear-by-Linear Association & 22.337 & 18 & .217 \\
\hline N of Valid Cases & 2.956 & 1 & .086 \\
\hline
\end{tabular}

The results show that in terms of actual target language use, the teachers differ significantly from each other $\left(X^{2}=17.875>X^{2}(6,0.01)=16.8\right)$, ranging from less than $50 \%$ to $100 \%$, with the mean about $83 \%$. 19 teachers, which account for about $60 \%$ of the total participants, claim to use more than $80 \%$ English in class, although only one teacher reports $100 \%$ target language employment. To the rest of the teachers, 11 of them use English ranging from $60 \%$ to $80 \%$, and the other two teachers use less than $60 \%$ English in class. The divergence among teachers is also significant with regard to the ideal proportions of target language use $\left(X^{2}=19.000>X^{2}(3,0.01)=11.3\right)$. About $94 \%$ teachers $(30$ teachers $)$ think it should be above $80 \%$. Among them, four teachers value $100 \%$ target language use. Only two teachers conceive the proportion to be between $70 \%$ and $80 \%$.

There seems to be some differences between the actual and ideal target language use, however, after the Chi-Square test, the attained result, $X^{2}=32.919<X^{2}(18,0.01)=34.8$, demonstrates that the difference is not significant. The teachers' actual target language is essentially consistent with the ideal proportions perceived by them. Most of the participants regard 91\%-99\% target language use as the most appropriate percentage, and their self-estimated actual teaching practices do conform to their beliefs. This phenomenon further testifies the claim that "the beliefs that teachers hold are likely to influence their decision making” (Kagan, 1992; Sato \& Kleinsasser, 1999, cited in Macaro, 2001, p.533).

\section{B. Reasons and Functions of Classroom Code-switching}

In the present research, the students of almost half of the participants don't specialize in English, and the majority of students considered by the participants are still in their first or second year in college. Therefore, $94 \%$ teachers treat their students' underdeveloped language ability as the most significant factor casting influence on the choice of language in class. This is consistent with Macaro's (2001, p.535) finding that "learner ability was a major factor in how much L1 was used". In the subsequent interview, the two teachers who claim to use less than $60 \%$ English in class complain that their students are mainly non-English majors, whose English proficiencies are so low that they can not even follow or understand simple teaching formulas, let alone unfamiliar subjects explained in English. Therefore, these students don't care (at least the teachers suppose so) whether English or Chinese is used to organize classes. "Too much English in class may even be complained by the students to the management", one teacher said. The other teachers also express the confusions caused by students' foreign language ability and the amount of English suitable to provide sufficient language input without causing too much cognitive load.

More than $65 \%$ participants (21 teachers) place teachers' foreign language proficiency in the second place, which reflects a stereotypical belief upheld by some Chinese foreign language teachers that English can only be effectively taught in English, and teachers' resorting to the mother tongue implies low language proficiency. Lesson content, mainly translation class, counts as the third factor creating the necessity for classroom code-switching. The rest of the factors are: belief about teaching ( $44 \%$ teachers), teaching activities conducted (41\% teachers), rules or policies (38\%), students' attitude $(38 \%)$, etc. About school policies, the only teacher, who reports $100 \%$ use of English, admits that Chinese also appears in her class, but she tries to dispel it due to the explicit regulations stipulated by her university authorities.

Two teachers mention peer influence, which is not identified by other research. I think social or cultural considerations can explain its appearance in Chinese foreign language context. For instance, according to the teacher who reports less than $50 \%$ target language use, they are frequently organized to sit in on classes given by more experienced teachers; after class, her colleagues usually exchange information about foreign language teaching. If the 
same teaching method or amount of target language is also employed by other teachers, she will feel quite secured.

About $69 \%$ teachers report that the L1 is mainly employed to teach grammar and abstract words. This is a much favored function of the L1 in foreign language class (Liu et al., 2004), and the purpose is to make the class be more time-cost efficient and easier to be understood. As to other functions of the L1, 38\% teachers use Chinese to highlight important points, $28 \%$ of them to check comprehension, $25 \%$ of them to establish teacher-student rapport, and $16 \%$ of them to organize tasks and classes, etc. TABLE 4 tabulates the factors affecting code-switching and the functions of the L1.

TABLE 4.

REASONS AND FUNCTIONS OF CLASSROOM CODE-SWITCHING

\begin{tabular}{|c|c|c|c|c|c|c|}
\hline Reasons & $\begin{array}{l}\text { Number of } \\
\text { teachers }\end{array}$ & $\begin{array}{l}\text { Percentage in } \\
\text { the total } \\
\text { participants }\end{array}$ & Functions of the L1 & $\begin{array}{l}\text { Number } \\
\text { of } \\
\text { teachers }\end{array}$ & $\begin{array}{l}\text { Percentage } \\
\text { in the total } \\
\text { participants }\end{array}$ & \\
\hline Belief about teaching & 14 & $44 \%$ & Check comprehension & 9 & $28 \%$ & \multirow{3}{*}{$\begin{array}{l}\text { Language } \\
\text { learning }\end{array}$} \\
\hline $\begin{array}{l}\text { Teachers' foreign language } \\
\text { proficiency }\end{array}$ & 21 & $66 \%$ & $\begin{array}{l}\text { Highlight important } \\
\text { points }\end{array}$ & 12 & $38 \%$ & \\
\hline Students' ability & 30 & $94 \%$ & $\begin{array}{l}\text { Teach grammar and } \\
\text { abstract words }\end{array}$ & 22 & $69 \%$ & \\
\hline Teaching methods used & 7 & $22 \%$ & Organize tasks and class & 5 & $16 \%$ & \multirow{7}{*}{$\begin{array}{l}\text { Class } \\
\text { manage- } \\
\text { ment }\end{array}$} \\
\hline Teaching activities conducted & 13 & $41 \%$ & $\begin{array}{l}\text { Establish } \\
\text { teacher-student rapport }\end{array}$ & 8 & $25 \%$ & \\
\hline Department or school policy & 12 & $38 \%$ & $\begin{array}{l}\text { Maintain discipline in } \\
\text { class }\end{array}$ & 4 & $13 \%$ & \\
\hline Lesson content & 18 & $56 \%$ & Save time and energy & 10 & $31 \%$ & \\
\hline Class size & 5 & $16 \%$ & & & & \\
\hline $\begin{array}{l}\text { Students' behavior and } \\
\text { attitude }\end{array}$ & 12 & $38 \%$ & & & & \\
\hline Peer influence & 2 & $6 \%$ & & & & \\
\hline
\end{tabular}

\section{Other Comments and Reflections on Code-switching}

In the interview two teachers, who claim to use more than $90 \%$ English in class, report that they only use Chinese to highlight important points or save time and energy. Time permitting, grammar and abstract words should all be taught in English. According to these two teachers, students need time to become familiar with the technical terms, and teachers can scaffold them by teaching and explaining those English terms separately in class. However, another teacher contends that it is not bad to resort to Chinese to explain grammatical knowledge and abstruse concepts for the purpose of reducing students' cognitive load. When further asked about understandings to maximal target use, they all equate it with $100 \%$ target language use, although they acknowledge that it is hard to adopt this target language-only method.

According to the questionnaire, all participants deem that their use of English or Chinese demonstrates positive correlations with students' language choice. The more English used by teachers, the more frequently their students will use English to communicate. This phenomenon is explained by some participants as "the power of teacher modeling". However, it doesn't follow that a causal relation exists between teachers' target language use and learners' foreign language proficiency. It just demonstrates that maximizing the target language use is a favorable practice in foreign language classrooms (Turnbull \& Arnett, 2002).

In terms of their feelings about speaking Chinese in class, more than half of them (59\%) report that they don't feel upset because their choices will benefit students' understanding, will facilitate the realization of teaching goals, etc. However, some teachers do confess that they feel a tinge of embarrassment when speaking Chinese. The reasons lie in the following aspects: their students expect them to speak English; their language competence will be doubted; they break the school regulation, or their students become dependent on Chinese, etc.

Most of the participants accentuate the importance of target language-only practice on the grounds that it will provide ample language input, and create authentic foreign language learning atmosphere. Two teachers explicitly propose that there be no need to switch code intentionally in class, and English-only method is flawless if teachers are capable enough to use English all the time. Another two teachers display strong socio-cultural awareness towards target language-only method, such as, worries about students' identity, or the marginalization of students with low language proficiency. The cognitive load engendered by target language-only method is also in the consideration of some teachers, although they only constitute a small part of the participants. As to worries about students' identity, in the interview, the teacher who mentions it indicates that this is a topic receiving increasing interest, especially in the developed countries. When further asked about the difference between classroom and social code-switching, this teacher thinks that they are basically the same, which is in sharp contrast with the majority of teachers' view that these two types of code-switching are different, with the former to assist language learning, while the latter to successfully finish social transactions. Therefore, teachers should be more prudent to classroom code-switching, and social code-switching can be casual and haphazard. All the participants are willing to acknowledge that these two forms of code-switching are pragmatic strategies with differing goals. However, they don't express the intention to cultivate them in class.

Cook (2001, p.403) classifies teaching goals into internal and external goals. The former involves the educational 
aims of the classroom itself, such as analyzing, inferring, etc., and the latter relates to actual target language use outside the classroom, say, commercial negation, field interpretation, etc. In the interview, six out of seven teachers (86\%) directly emphasize the importance of external goals of foreign language learning. According to them, using English appropriately in future communication, and using it as an instrument to aid knowledge acquiring in other fields is the ultimate goal of language learning. However, the interview reveals that the teachers are more inclined to associate classroom code-switching with internal goals of language learning. One teacher plays a joke that examination should also become a goal, which reflects the awkward exam-guided or exam-orientated teaching situation in China.

\section{DISCUSSION}

Code-switching is commonplace in Chinese foreign language teaching context due to the fact that among the 32 participants, only one teacher claims to stick to English all the time in class. When code-switching is resorted to, it can not only be applied to language learning but class management (TABLE 4). In the light of this situation, I can't agree with Turnbull (2001, p.537) more that there is no need to "license teachers to use the L1; many do so in any case". If the L1 can be allowed to appear in all the occasions mentioned above, how can we guarantee the language input demanded by our students? In Chinese foreign language context, classrooms are still the major places where students can be exposed to English. Therefore, in order to guarantee sufficient language input, maximal use of the target language should continue to be encouraged. However, it is impractical to equate it with total exclusion of the L1.

In the present research, almost all teachers acknowledge that Chinese does find its place in their teaching practice, and they can also justify their alternation of teaching codes, but most of them are still reluctant to treat the L1 as a useful pedagogical resource. This attitude towards the L1 may originate from their understanding of the authenticity of foreign language learning atmosphere. In the questionnaire and interview, many teachers mention the destructive effect of classroom code-switching in establishing a genuine target language learning atmosphere. According to them, an ideal, authentic foreign language learning atmosphere can only be realized through the target language-only method.

So far it is still hard to define maximal target language use in terms of its quantitative and qualitative respects due to the various factors influencing the choice of teaching codes. However, in Chinese tertiary English education, considering the distinction between language- and content-subject classes, together with the language subject-centered feature of Chinese foreign language teaching, we can tentatively come up with some suggestions. For instance, in language learning, Chinese can be temporarily employed when grammatical knowledge or abstruse concepts are explained to students, because the priority in this situation is to make the students understand the subject matter. However, other tasks such as comprehension checking, emphasizing and class management should all be done in English, because they constitute activities frequently involved in authentic social communication. Familiarity with them can also prepare students well for future communication beyond class. Besides, before the use of the L1, other forms of foreign languages, including paralanguages such as repetition, ellipsis (L2 strategy), facial expression and gesture, etc. can also be borrowed to express the intended meaning. Of course, this is just a goal set to guide the choice of teaching codes. In this course, Chinese foreign language teachers should assume greater responsibilities in decision making, and teacher education and policy guidance will become more and more pressing.

In the present research, the average classroom target language use is $83 \%$, which is consistent with most participants' belief that more than $80 \%$ English will be most helpful to their students. Compared with the target language use in other research, such as 67.9\% in Duff and Polio's (1990) study, the ratio of foreign language use in the present study is comparatively high. However, we can't ignore the reality that 7 teachers, who account for $22 \%$ of the research sample, still employ relatively limited amount of the target language in class. Besides, the education involved in the present research is tertiary education. According to Atkinson (1987), the most profitable ratio for the L1 and target language use in class should be about 5\% to 95\% respectively. Macaro (2005) also suggests that beyond 10\%-15\% L1 use in foreign language class, the nature of code-switching will be spoiled. Therefore, there are still rooms for Chinese college English teachers to improve in terms of the target language use in class, especially for those who teach English majors.

\section{CONCLUSIONS}

In Chinese tertiary EFL teaching context, teachers usually switch code in class with the consideration of their students' language proficiency, which is not fully fledged, and the L1 is mainly employed to teach grammar and abstract concepts. Although classroom code-switching still tends to be regarded as an undesirable practice, it becomes acceptable to many teachers on the grounds that sensible use of the L1 may benefit foreign language instruction. Besides, there are only $12 \%$ teachers who think that target language-only method can be ideally realized in Chinese EFL settings, which demonstrates that most Chinese college English teachers have a strong awareness of their statuses as non-native speaker (NNS) English teachers. It is indicated that research in this group of teachers is becoming a recent phenomenon, which can be launched from the perspective of teachers' self-perceptions and students' attitudes (Braine, 2005). It is significant that some teachers, although a small number of them, notice the socio-cultural factors behind foreign language teaching, such as the issue of student identity, which are thought-provoking topics facing NNS teachers and learners.

Through understanding Chinese college English teachers' perceptions towards the functions, reasons and proportions of classroom code-switching, the present research intends to, on the one hand, arouse attentions from the educational 
authorities as to the unavoidable phenomenon of classroom code-switching in Chinese EFL settings, on the other, to lay a solid basis for future research. As is mentioned in the beginning, the present research is only a pilot study and further research will be conducted about students' attitude toward code-switching, or teachers' actual code-switching practices in class. In that case, questions such as the discrepancy between teachers' behavior and belief, relations between students' and teachers' belief, etc. can be adequately analyzed.

\section{REFERENCES}

[1] Atkinson, D. (1987). The mother tongue in the classroom: A neglected resource? ELT Journal, 41/4, 241-247.

[2] Auerbach, R. E. (1993). Reexamining English only in the ESL classroom. TESOL Quarterly, 27/1, 9-32.

[3] Braine, G (2005). A history of research on non-native speaker English teachers. In E. LIurda (Eds.), Non-native Language Teachers: Perceptions, Challengers and Contributions to the Profession. New York: Spring Science, 13-23.

[4] Cook, V. (2001). Using the first language in the classroom. The Canadian Modern Language Review, 57/3, 403-423.

[5] Department of Higher Education in Ministry of Education. (2007). College English Curriculum Requirements. http://www.edu.cn/gao_jiao_news_367/20070927/t20070927_256807.shtm.1 (accessed 3/9/2008).

[6] Duff, P. \& C. G. Polio. (1990). How much foreign language is there in the foreign language classroom? The Modern Language Journal, 74/2, 154-166.

[7] Duff, P. \& C. G. Polio. (1994). Teachers' language use in university foreign language classroom: A qualitative analysis of English and target language alternation. The Modern language Journal, 78/3, 313-326.

[8] Ferguson, G (2003). Classroom code-switching in post-colonial contexts: Functions, attitudes and policies. AILA Review, 16, 38-51.

[9] Gumperz, John J. (1982). Conversational code-switching. In J. Gumperz (Eds.), Discourse Strategies, 59-99.

[10] Harbord. J. (1992). The use of the mother tongue in the classroom. ELT Journal, 46/4, 350-355.

[11] Krashen, S. \& Terrell, T. (1983). The natural approach. Englewood Cliffs, NJ: Prentice Hall.

[12] Lin, A. M. Y. (2000). Deconstructing "mixed code". In Li, D. C. S., Lin, A. M. Y., \& Tsang, W. K. (Eds.), Language and education in postcolonial Hong Kong. Hong Kong: Linguistic Society of Hong Kong, 179-194.

[13] Liu, D. et al. (2004). South Korean high school English teachers' code switching: Questions and Challenges in the drive for maximal use of English in Teaching. TESOL Quarterly, 38/4, 605-638.

[14] Long, M. (1996). The role of the linguistic environment in second language acquisition. In W. Ritchie \& T. Bhatia (Eds.), Handbook of second language acquisition. San Diego: Academic Press, 413-468.

[15] Macaro, E. (1997). Target language, collaborative learning and autonomy. Clevedon, UK: Multilingual Matters.

[16] Macaro, E. (2001). Analyzing student teachers' code-switching in foreign language classroom: Theories and decision making. Modern language Journal, 85, 531-548.

[17] Macaro, E. (2005). Code-switching in the L2 classroom: A communication and learning strategy. In E. Llurda (Eds.), Non-native Language Teachers: Perceptions, Challengers and Contributions to the Profession. New York: Spring Science, 63-84.

[18] MacDonald, C. (1993). Using the target language. Cheltenham, UK: Mary Glasgow Publications.

[19] Mesthrie, R. (2000). Introducing sociolinguistics. Edinburgh: Edinburgh University Press.

[20] Ministry of Education. (1996). Teaching curriculum for English majors at elementary level. Shanghai: Shanghai Foreign Language Education Press.

[21] Ministry of Education. (2000). Teaching curriculum for English majors. http://www.bfsu.edu.cn/chinese/site/gxyyzyxxw/zywj/yyjxdg.htm (accessed 3/9/2008).

[22] Phillipson, R. (1992). Linguistic Imperialism. New York: Oxford University Press.

[23] Rubdy, R. (2007). Singlish in the school: An impediment or a resource? Multilingual and Multicultural Development, 28/4, 308-317.

[24] Sakui, K. \& Gaies, S. (2003). A case study: Beliefs and metaphors of a Japanese teacher of English. In P. Kalaja \& A. M. F. Barcelos (Eds.), Belief about SLA: New research approaches. Dordrecht: Kluwer Academic Publishers, 153-170.

[25] Simon, D. (2000). Towards a new understanding of code-switching in the foreign language classroom. In R. Jacobson (Eds.), Code-switching Worldwide II. Berlin: Mouton de Gruyter, 311-342.

[26] Swain, M. (1993). The output hypothesis: Just reading and writing aren't enough. Canadian Modern Language Review, 50, 158-164.

[27] Swain, M. \& S. Lapkin. (2000). Task-basked second language learning: The uses of the first language. Language Teaching Research, 4/3, 251-274.

[28] Turnbull, M. (2001). There is a role for the L1 in second and foreign language teaching, but.... The Canadian Modern Language Review, 57/4, 532-540.

[29] Turnbull, M. \& K. Arnett. (2002). Teachers' uses of the target and first languages in second and foreign language classrooms. Annual Review of Applied Linguistics, 22, 204-218.

[30] Van der Walt. (1997). English as a language of learning in South Africa: Whose English? Whose culture? Language Awareness, 6, 183-197.

[31] Woods, Devon. (2003). The social construction of beliefs in the language classroom. In P. Kalaja \& A.M.F. Barcelos (Eds.), Beliefs about SLA: New research approaches. Dordrecht: Kluwer Academic Publishers, 201-229. 
Xiaoli Cheng, received her MA degree from Sichuan International Studies University in Chongqing, China. She also got a diploma of teaching methodology from National Institute of Education of Nanyang Technological University in Singapore. Now she is a lecturer at the School of Foreign Language and Literature, Chongqing Normal University. Her research interests mainly include second language acquisition, teaching methodology, pragmatics, etc. 